\title{
Keragaman Spesies Pohon sebagai Karakteristik Lansekap Hutan Lindung Bukit Rigis (Studi Kasus: Areal Kelola Kelompok Hutan Kemasyarakatan (HKm) Bina Wana)
}

\section{Tree Species Biodiversity as a Landscape Characteristic of Bukit Rigis Protected Forest (Case Study: Management Area of Bina Wana Community Forestry)}

\author{
Anggun Freshelia ${ }^{1 *}$, Christine Wulandari $^{1,2}$, Dian Iswandaru ${ }^{1}$, Yulia Rahma Fitriana ${ }^{1}$ \\ 1Jurusan Kehutanan Fakultas Fakultas Pertanian Universitas Lampung, Bandar Lampung, 35141 \\ ${ }^{2}$ Magister IImu Kehutanan Fakultas Pertanian Universitas Lampung, Bandar Lampung, 35141 \\ "Email: fresheliaanggun@gmail.com
}

Disubmit: 15 September 2019 Direvisi: 1 Januari 2020 Diterima: 29 Januari 2020

\begin{abstract}
Abstrak: Lanskap dikenal dengan karakteristik bentang alam yang didominasi oleh hutan yang wilayahnya meliputi dari daerah hulu hingga ke bagian hilir dari suatu Daerah Aliran Sungai (DAS). Kelestarian hutan memerlukan model pengelolaan lanskap yang baik dengan memperhatikan fungsi hutan lindung, tata air dan pengelolaan yang berkelanjutan. Sebab kelestarian hutan hanya ditentukan oleh pilihan sistem silvikultur saja melainkan kekompakkan fungsi hutan sebagai suatu kesatuan ekosistem yang terdiri atas aspek sosial,ekonomi dan ekologi. Penelitian ini bertujuan menganalisis karakteristik ekologi lanskap hutan lindung Register 45B Bukit Rigis di areal kelola Kelompok HKm Binawana. Penelitian ini menggunakan metode analisa GIS dan deskripsi kuantitatif. Berdasarkan hasil penelitian menunjukkan bahwa karakteristik ekologi hutan lindung Bukit Rigis adalah sebagai berikut: terdapat 27,58\% tutupan hutan, dimana da lebih dari tiga stratifikasi tajuk, dan 2 jenis mayoritas spesies di Lahan HKm Binawana yaitu kemit (Sarcosperma paniculatum), randu (Ceiba pentandra). Selain itu, diperlukan sosialisasi tentang kelestarian $\mathrm{HKm}$ maupun hutan lindung tersebut.
\end{abstract}

Kata kunci: hutan kemasyarakatan, hutan lindung, karakterstik ekologi, pohon, tutupan hutan.

\begin{abstract}
Characteristic of landscape known as a landscape dominated by forest area covers from the upstream to downstream of a Watershed (Daerah Aliran Sungai). Forest sustainability requires a good landscape management model that takes into account the function of protected forest, water managejment and sustainable management. The preservation of forests is not only determined by the silvicultural system but also the cohesiveness of forests function as an ecosystem which considered by social, economic and ecology aspect. The purpose of this research was to analyze the ecological characteristics of the protected forest landscape Register 45B Bukit Rigisin Binawana Community Forest. This research was used GIS and descriptive quantitative method. Based on the survey results showed that the characteristics of protected forest Bukit Rigis were about $27.58 \%$ forest cover, where there are more than three stratification of the canopy, and the majority of the species on land Binawana community forestry were Kemit(Sarcosperma paniculatum) and Randu (Ceiba pentandra). In addition, socialization on the sustainability of $\mathrm{HKm}$ and the protected forest is needed.
\end{abstract}

Keywords: community forestry, characteristics of the ecology, forest cover, trees, protected forests. 


\section{PENDAHULUAN}

Perbandingan jumlah penduduk yang tidak seimbang dengan luasan lahan pertanian, keterbatasan lapangan kerja, dan minimnya pendapatan mendorong sebagian masyarakat untuk merambah hutan dengan mengabaikan kaidah-kaidah konservasi lingkungan (Wulandari, 2010). Hal tersebut menjadikan hutan rusak (Ali, Kharis dan Karlina, 2018), sehingga dikeluarkanlah peraturan yang mengatur pemanfaatan sumberdaya hutan berbasis masyarakat di hutan negara melalui Permen LHK nomor 83 tahun 2016 tentangPerhutanan Sosial (PS). Terdapat lima konsep yang dijelaskan yaituHutan Desa, Hutan Tanaman Rakyat, Kemitraan konservasi, Hutan adat dan Hutan Kemasyarakatan. Kelima konsep tersebut diharapkan dapat menjadikan masyarakat sebagai mitra menuju pengelolaan hutan lestari dan masyarakat sejahtera (Sanjaya, Wulandari dan Herwanti, 2017).

Salah satu $\mathrm{HKm}$ tertua di Indonesia adalah $\mathrm{HKm}$ yang terletak di Provinsi Lampung.Hal tersebut didasari karena sebagian besar kawasan hutan di Provinsi Lampung telah dirambah dan secara perlahan-lahan pemanfaatannya berubah menjadi lahan budidaya baik tanaman semusim maupun perkebunan (kopi, coklat) (Sanudin et al. 2016). Oleh karena itu Lampung menjadi salah satu HKm yang disahkan pada awal pembentukan skema perhutanan sosial, termasuk HKm Bina Wana.

HKm Bina Wana yang berada di Pekon Tribudi Syukur Kecamatan Sumber Jaya memiliki izin (IUPHKm) Nomor B/1454/KPTS/III/2007 dengan luas total 645 ha, 470 ha diantaranya lahan budidaya (Ayudanti, 2017). Sebagian penggarap menilai HKm menjadi usaha budidaya yang berfokus pada faktor produksi/ekonomi (Wulandari et al. 2009). Faktanya, seluruh HKm di Provinsi Lampung adalah hutan lindung yang memiliki fungsi semulanya sebagai penyangga kehidupan, khususnya fungsi hidrologi yang salah satunya aspek ekologi.

Kawasan Hutan Lindung (HL) Register 45 B Bukit Rigis yang ditetapkan sebagai kawasan hutan melalui Besluit Residen nomor 117 tanggal 19 Maret 1935 memiliki luas 8.295 ha, merupakan kawasan hutan yang ekosistemnya paling berpengaruh karena letaknya ditengah dan hampir menutupi wilayah sub-DAS Way Besai (Pasya, 2004). Menurut Konsorsium Pendukung Sistem Hutan Kerakyatan (2015), keberadaan HL Bukit Rigis penting sebagai penyangga kehidupan sosial, ekonomi, dan ekologi.

Secara ekologi, perubahan penggunaan lahan akan membentuk karakteristik struktur, fungsi dan dinamika lanskap yang baru (Prastiyo, Kaswanto dan Arifin, 2017), termasuk perubahan lahan dari Hutan lindung menjadi hutan kemasyarakatan. Menurut Wulandari (2012) pentingnya perolehan data yang valid atas pengembangan $\mathrm{HKm}$ maka diperlukan analisis dan monitoring evaluasi, salah satunya lanskap ekologi. Oleh karena itu, diperlukan penelitian mengenai karakteristik ekologi lanskap Hutan Lindung Register 45B Bukit Rigis berupa tutupan lahan dan keanekaragaman jenis pohon pada salah satu $\mathrm{HKm}$ di dalamnya, yaitu HKm Bina Wana. 


\section{METODE PENELITIAN}

\section{Bahan}

Penelitian ini dilakukan di Pekon Tribudi Syukur Kecamatan Sumber Jaya Kabupaten Lampung Barat, Provinsi Lampung. Penelitian ini dilaksanakan dari bulan Juli sampai September 2019. Peralatan yang digunakan pada penelitian ini, meliputi handphone, kamera digital, Global Positioning System (GPS), seperangkat komputer, software berupa ArcMap 10.4, Microsoft Word 2010, danMicrosoft Excel 2010 for Windows. Bahan yang digunakan dalam penelitian ini adalah data hasil inventarisasi jenis pohon di lahan garapan $\mathrm{HKm}$ dan peta penutupan lahan Hutan Lindung Register 45B Bukit Rigis tahun 2017 dari Kementerian Lingkungan Hidup dan Kehutanan (KLHK).

\section{Pelaksanaan Penelitian}

Data penelitian terdiri atas data primer dan data skunder. Data primer diperoleh dari hasil pengamtan langsung di lapangan dengan metode wawancara pada Sub Kelompok $1 \mathrm{HKm}$ Bina Wana yang terlibat dalam pengelolaan lahan budidaya. Data primer meliputi keragaman jenis pohon dan kondisi topografi. Data skunder diperoleh dari berbagai sumber terutama instansi pemerintahan berupa data tutupan lahan.

Pengklasifikasi penutupan lahan berdasarkan potret udara tahun 2017. Klasifikasi ini dibagi menjadi sepuluh kelas yaitu perairan, sawah, rawa, tanah terbuka, perkebunan, pemukiman, petanian lahan kering campuran, belukar, hutan lahan kering primer dan hutan lahan kering sekunder. Selanjutnya dilakukan pengambilan titik sesuai dengan intepretasi kondisi penutupan lahan di lapang. Proses klasifikasi penutupan lahan dilakukan menggunakan perangkat lunak Erdas dengan sistem koordinat yang digunakan dalam koreksi geometrik adalah UTM dengan datum WGS 1984 zona 48S. Intepretasi visual penutupan lahan dilakukan dengan analisis menggunakan aplikasi Erdas ke dalam bentuk klasifikasi kelas penutupan lahan. Selanjutnya tahap pembuatan layout menggunakan perangkat lunak ArcGIS kemudian diinterpretasikan sebagai peta penutupan lahan hutan di Bukit Rigis pada tahun 2017.

Selain itu, diperlukan inventarisasi pohon dilakukan dengan pembuatan plot ukuran $20 \mathrm{~m}$ x $20 \mathrm{~m}$ dengan teknik purposive sampling with random start (Gambar 1). Pada saat pengambilan data pohon dicatat nama lokal, diameter dan tingginya serta informasi tambahan terkait manfaat dari pohon tersebut.

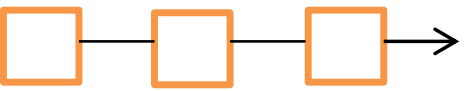

\section{Gambar 1. Sampling area}

Keterangan

= Plot pengamatan pohon $(20 \mathrm{~m} \times 20 \mathrm{~m})$

$=$ Jarak antar plot $(20 \mathrm{~m})$

\section{Analisis Data}

Karakteristik ekologi lanskap dianalisis dengan menggunakan dua cara yaitu analisis spasial dan analisis keanekaragaman jenis pohon. Analisa spasial (GIS) digunakan untuk mengidentifikasi salah satu elemen lanskap yaitu luas tutupan lahan. Hasil perhitungan luas tutupan lahan dari masing-masing kelas tutupan 
lahanpada tabel atribut perlu disimpan dalam bentuk Excel Workbook for Windows agar selanjutnya dapat diolah dan dianalisis bersama untuk mengetahui masingmasing kelas penutupan lahan akan dilihat dan perbandingannya terhadap total luasan keseluruhan (Yekti, Sudarsono dan Subiyanto, 2013). Hasilnya diperoleh persentase penutupan lahan dari masing-masing kelas yaitu perairan, sawah, rawa, tanah terbuka, perkebunan, pemukiman, petanian lahan kering campuran, belukar, hutan lahan kering primer dan hutan lahan kering sekunder.

Analisa keragaman spesies pohon pada blok budidaya serta sumber mata air di sekitar HKm menggunakan penentuan Indeks Nilai Penting (INP) dihitung dengan menggunakan rumus sebagai berikut (Hardjosuwarno, 1990). Kerapatan diartikan sebagai jumlah individu persatuan luas yang dinyatakan dalam $\mathrm{m}^{2}$ atau hektar. Presentasi densitas total suatu spesies diartikan dengan Kerapatan Relatif (KR) dengan rumus sebagai berikut:

$K=\frac{\text { Eindividu suatu jenis }}{\text { Luas total plot pengamatan }}$

$K R=\frac{K \text { suatu spesies }}{K \text { seluruh spesies }} \times 100 \%$

Frekuensi adalah presentasi hadirnya suatu spesies dalam plot pengamatan per jumlah semua plot pengamatan. Presentase frekuensi ditunjukkan dengan frekuensi relatif. Rumusnya sebagai berikut.

$F=\frac{\sum \text { Plot terdapatnya suatu jenis }}{\sum \text { plot pengamatan }}$

$F R=\frac{\text { Frekuensi suatu spesies }}{\text { Frekuensi semua spesies }} \times 100 \%$

Basal area diartikan dengan besaran derajat penguasaan ruangberupa luas area yang ditumbuhi oleh sejenis tumbuhan (Kusmana, 1997). Rumusnya sebagai berikut: $D=\frac{\text { Luas basal area }}{\text { luas total plot pengamatan }}$

$D \%=\frac{\sum \text { Dominansi suatu jenis }}{\sum \text { dominansi seluruh jenis }} \times 100 \%$

Keanekaragaman jenis akan dinyatakan dalam indeks Shannon-Wiener $\left(H^{\prime}\right)$ yang dihitung menggunakan rumus sebagai berikut :

$H^{\prime}=-\Sigma p i \operatorname{Ln} p i$

Dimana pi adalah pembagian jumlah individu jenis ke-i terhadap jumlah individu total (Stiling, 1996). Magurran (1988) mengatakan kisaran nilai hasil perhitungan indeks keanekaragaman $\left(\mathrm{H}^{\prime}\right)$ sebagai berikut jika:
a. $\mathrm{H} \geq 3$
: Keragaman spesies tinggi
b. $1<\mathrm{H}<3$
: Keragaman spesies sedang
c. $\mathrm{H} \leq 1$
: Keragaman spesies rendah

\section{HASIL DAN PEMBAHASAN}

\section{Tutupan Lahan}

Beradasarkan analisa GIS dari foto udara tahun 2017, diperoleh data primer tentang luas tutupan hutan di Hutan Bukit Rigis seluas 27,58\% (Gambar 2). Berdasarkan Vebrist dan Pasya (2004) luas tutupan hutan Bukit Rigis pada tahun 2004 sebesar $25 \%$. Hal ini menunjukkan bahwa adanya peningkatan tutupan lahan.

Peningkatan tutupan lahan hutan dari tahun 2004 sampai dengan tahun 2017 sebesar 2,58 \% menunjukkan bahwa HKm memberikan kontibusi terhadap 
perluasan tutupan lahan hutan sebab pada kelompok tani $\mathrm{HKm}$ melakukan penanaman di areal hutan. Menurut Wulandari et al. (2009) wilayah HKm pada kawasan hutan lindung biasanya merupakan areal berbukit dan bergunung-gunung sehingga menanam berbagai tumbuhan yang memiliki strata tajuk lengkap merupakan kewajiban bagi setiap kelompok tani HKm. Hal tersebut dapat menjadi salah satu penyebab perluasan tutupan HL Register 45B Bukit Rigis.
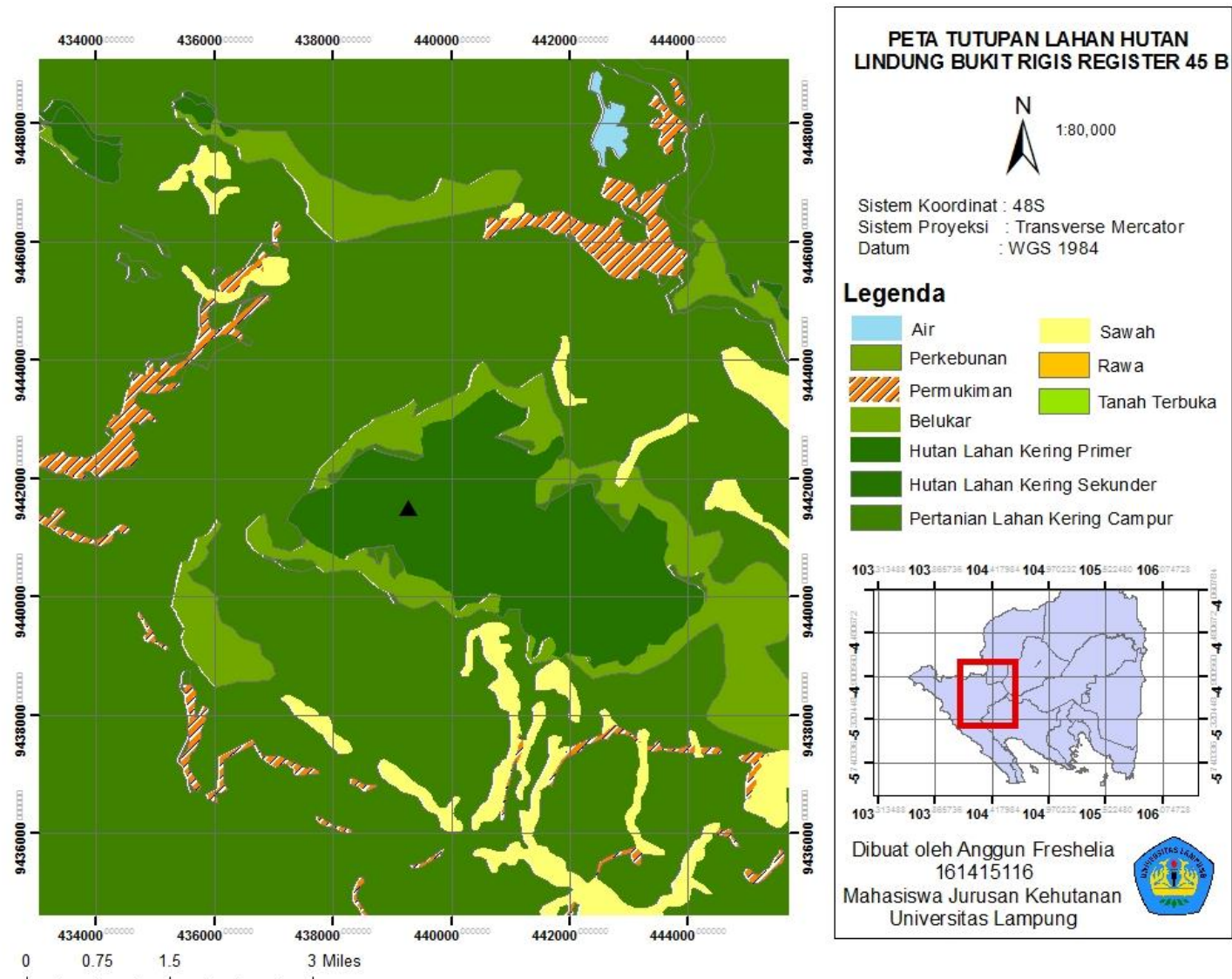

Gambar 2. Peta penutupan lahan HL Bukit Rigis Register 45B pada tahun 2017.

Menurut Syam et al. (2017), peran aktif pemerintah sangat diperlukan untuk membentuk kebijakan yang berbasis lingkungan, khususnya hutan lindung sebagai kawasan yang perlu dipertahankan keberadaannya karena fungsi berpengaruh aspek ekologis. Blok budidaya $\mathrm{HKm}$, perlu dilakukan upaya himbauan untuk tidak melakukan pengolahan lahan dengan kemiringan lebih dari 45 derajat agar terhindar dari erosi sehingga dapat mencegah pengurangan tutupan lahan akibat lahan tidak tidak stabil (Sanjaya, Wulandari dan Herwanti, 2017).

\section{Keanekaragaman Spesies Pohon}

Berdasarkan hasil penelitian, tegakan pohon di areal HKm Bina Wana terdiri dari 12 spesies (Tabel 1). Jumlah spesies lebih dari 10 berarti bahwa pohon yang terdapat di HKm Bina Wana bervariasi. Menurut Naisumu, Seran dan Ledheng (2018) jumlah spesies lebih dari 10 mencirikan tumbuhan yang bervariasi, hal ini dapat disebabkan oleh terjaganya keadaan tegakan pada $\mathrm{HKm}$ Binawana. Tabel 1 juga menunjukkan jenis yang berjumlah paling banyak yaitu kemit ( $S$. paniculatum) 8 individu, randu (C. pentandra) 2 individu, cendana ( $S$. album) sebanyak 2 individu. 
Tingkat banyaknya jumlah individu akan berbanding lurus dengan individu yang sering hadir pada lahan.

Kemit (S. paniculatum) mendominasi di areal penelitian karena mampu beradaptasi dan toleransi terhadap kondisi lingkungan lebih baik dari jenis lainnya. Hasil penelitian menunjukkan bahwa kemit (S. paniculatum) mampu beradaptasi di lingkungan setempat (Naisumu, Seran dan Ledheng, 2018). Spesies yang memiliki dominansi paling besar, akan memperoleh Indeks Nilai Penting (INP) paling besar pula (Indriyanto, 2006). Tabel 1 menunjukkan INP terbesar diperoleh dari kemit (S. paniculatum) $(80,95 \%)$, randu (C. pentandra) $(63,01 \%)$ dan cendana (S. album) $(20,61 \%)$ sedangkan spesies yang lainnya memiliki INP di bawah $20 \%$.

Hasil penelitian menunjukkan bahwa kemit (S. paniculatum) adalah spesies yang paling dominan di wilayah penelitian karena spesies ini ditemukan pada semua plot pengamatan. Hasil ini menunjukkan bahwa kemit ( $S$. paniculatum) menjadi jenis spesies yang cukup dominan pada kanopi tengah hutan dengan tipe $\mathrm{A}, \mathrm{B}$ dan $\mathrm{C}$ (Pitopang, 2012). Mongabay (2019) melaporkan bahwa kisaran tinggi pohon kanopi tipe A, B dan C antara 4-30m.

Tabel 1. Keanekaragaman jenis pohon di blok budidaya HKm Bina Wana.

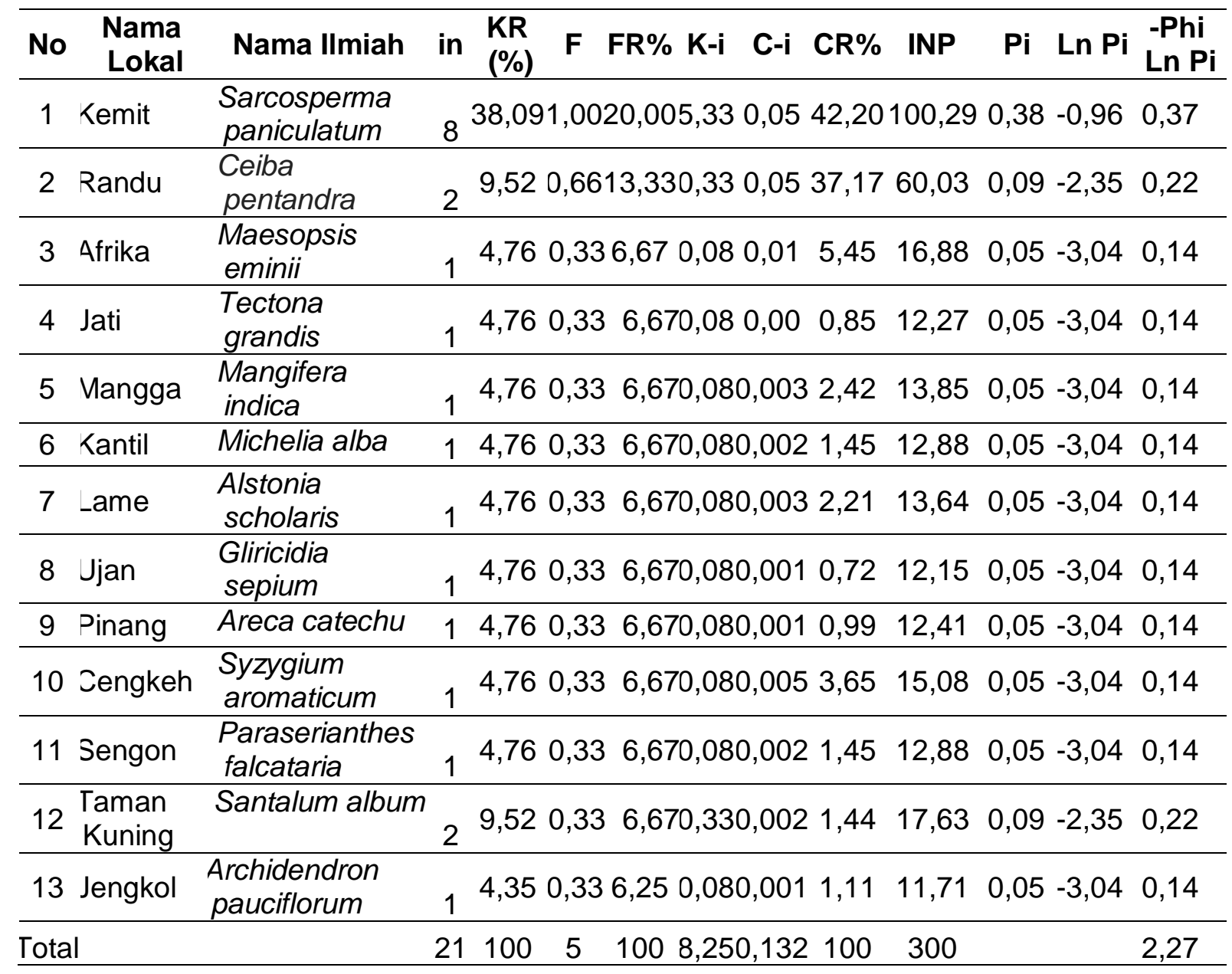




\section{SIMPULAN}

Berdasarkan perbandingan data tahun 2004 dan 2017 diketahui bahwa ekologi lanskap hutan lindung Bukit Rigis di areal kelola Kelompok HKm Bina Wana memiliki tutupan lahan seluas27,58\%.Indeks keanekaragaman pohon dikategorikan sedang $(2,39)$ adanya 12 jenis spesies dan dominansi oleh Kemit (S. paniculatum). Perlu adanya sosialisasi mengenai penjagaan dan kelestarian ekologi lahan $\mathrm{HKm}$.

\section{DAFTAR PUSTAKA}

Ayudanti, K. 2017. Analisis Efektivitas hutan Kemasyarakatan dalam Meningkatkan Pendapatan dan Tingkat Konsumsi Masyarakat Menurut Perspektif Ekonomi Islam. Skripsi. Lampung: Universitas Lampung. 120 pp.

Ali, M., Kharis, A., dan Karlina, D. 2018. Implementasi undang-undang no 18 tahun 2013 tentang pencegahan dan pemberantasan perusakan hutan (Studi kasus tentang faktor-faktor yang mempengaruhi masyarakat melakukan perambahan hutan di desa lunyuk ode kecamatan lunyuk kabupaten Sumbawa besar). Jurnal IImu Administrasi Publik. 6(2): 153-165.

Hardjosuwarno, S. 1990. Dasar-Dasar Ekologi Tumbuhan. Fakultas Biologi UGM. Yogyakarta.

Indriyanto. 2006. Ekologi Hutan. Bumi Aksara. Jakarta.

Kusmana, C. 1997. Ekologi dan ekosistem mangrove. Jurusan Managemen Hutan IPB Press. Bogor.

Konsorsium Pendukung Sistem Hutan Kerakyatan. 2015. Dari Cap Perambah menjadi Pelestari Hutan Lindung. Artikel. http://kpshk.org /2015/02/09/dari-capperambah- menjadi-pelestari-hutan-lindung/(diakses pada tanggal 1 September 2019)

Magurran, A. E. 1988. Why Diversity? Ecological diversity and its measurement. Springer. $1-5$.

Mongabay. 2019. Stratifikasi.Artikel. https://www.mongabay.co.id/\%20stratifikasi/ (diakses pada tanggal 3 September 2019).

Naisumu, Y. G., Seran, Y. Y., dan Ledheng, L. 2018. Komposisi dan keanekaragaman jenis pohon di hutan lindung lapeom kabupaten timor tengah utara. Jurnal Saintek Lahan Kering. 1(1): 4-6.

Pasya, G. 2004. Sistem Pendukung Negosiasi (SPN) Suatu Pendekatan untuk Pemecahan Masalah Konflik di Kawasan Hutan. Seminar Kebijakan Pengelolaan Sumberdaya Alam dan Aktivitas Sosial Ekonomi dalam Kaitannya dengan Penyebab dan Dampak Kebakaran Hutan dan Lahan di Sumatera. ICRAF, Ditjen PHKA Departemen Kehutanan, European Union, Bappeda Provinsi Lampung dan CIFOR. Bandarlampung. $19 \mathrm{pp}$.

Pitopang, R. 2012. Impact of forest disturbance on the structure and composition of vegetation in tropical rainforest of sentral sulawes, Indonesia. Journal of Biological Diversity. 13(4): 178-189.

Prastiyo, Y. B., Kaswanto dan Arifin, H. S. 2017. Analisis ekologi lanskap agroforestri pada riparian sungai ciliwung di kota bogor. Jurnal Lanskap Indonesia. 9(2): 8190. 
Rehulina, Purwoko, A., Latifah, S. 2013. Komposisi dan stratifikasi vegetasi pohon di hutan pendidikan universitas sumatera utara, tongkoh, kabupaten karo, provinsi sumatera utara. Jurnal USU.1(1):1-5.

Sanjaya, R., Wulandadri, C dan Herwanti, S. 2017. Evaluasi Pengelolaan Hutan Kemasyarakatan $(\mathrm{HKm})$ pada Gabungan Kelompok Tani Rukun Lestari Sejahtera di Desa Sindang Pagar Kecamatan Sumberjaya Kabupaten Lampung Barat. Jurnal Sylva Lestari. 5(2): 30-42.

Sanudin, Awang, S. A., Sandono, R dan Purwanto, R. H. 2016. Perkembangan hutan kemasyarakatan di provinsi lampung. Jurnal Manusia dan Lingkungan. 23 (2) : $276-283$.

Stiling, P.D. 1996. Ecology: Theories and Applications 2nd. Prentice Hall. New Jersey.

Syam, T., Darmawan, A., Banuwa, I. S dan Ningsih, K. 2017. Pemanfaatan citra satelit dalam mengidentifikasi perubahan penutupan lahan : studi kasus hutan lindung register 22 way waya lampung tengah. Jurnal Globe. 14(2): $146-156$.

Vebrist, B dan Pasya, G. 2004. Perspektif sejarah status kawasan hutan, Konflik dan negosiasi di sumberjaya, lampung barat -propinsi lampung. Agrivita. 26 (1) : 20 28.

Wulandari, C., Dinas Kehutanan Provinsi Lampung, Sulistiantoro, E., Nuch, I. M., Syahrani, J., Saroso, O., Putro, P., Pahlawanti, R., Suhendri, Warsito. 2009. Hutan Kemasyarakatan Melestarikan Hutan untuk Kesejahteraan Rakyat Catatan 10 Tahun Program HKm di Provinsi Lampung. Watala. Bandarlampung. 122 halaman.

Wulandari, C. 2010. Studi persepsi masyarakat tentang pengelolaan lanskap agroforestri di sekitar sub das way besai, provinsi lampung. Jurnal IImu Pertanian Indonesia. 15 (3): 137 - 140.

Wulandari, C. 2012. Diversifikasi hasil agroforestry di sekitar Hutan Sumberja adan Daerah Aliran Sungai (DAS) Way Besai dalam "Pengelolaan Hutan dan Daerah Aliran Sungai Berbasis Masyarakat: Pembelajaran dari Way besai Lampung" Editor Banua dan Abidin. Balai Pengelolaan Daerah Aliran Sungai Way Seputih Way Sekampung. Bandarlampung.

Yekti, A., Sudarsono, B., Subiyanto, S. 2013. Analisis Perubahan Tutupan Lahan DAS Citanduy Dengan Metode Penginderaan Jauh. Jurnal Geodesi Unip. 2 (4): $1-9$. 